\title{
Pedagogy for Professional Learning
}

\author{
Iain Doherty ${ }^{1}$ \\ ${ }^{1}$ Director, eLearning Pedagogical Support Unit, The University of Hong Kong
}

\begin{abstract}
Professional learning is defined as formal or informal learning that leads to the knowledge, skills and personal attributes necessary to carry out professional duties. This paper critically reflects on the pedagogical approach underlying an eLearning Certificate Course. The aim of the course was to teach faculty based eLearning officers the necessary practical and theoretical skills to fulfill their roles in supporting Faculties with eLearning initiatives. Whilst the course was successfuljudged in terms of the pass rate and course evaluations - the underlying pedagogy could be improved. The proposed revisions are discussed.
\end{abstract}

Keywords: professional learning; professional development; eLearning;

\section{Introduction}

In 2011 The University of Hong Senate endorsed an eLearning strategy to be implemented commencing 2012. The aim of the eLearning strategy is to enhance participants' learning experiences through the creative, appropriate and effective use of technologies. A new unit - the eLearning Pedagogical Support Unit (EPSU) was set up in January 2012 to provide and co-ordinate eLearning pedagogical support to Faculties, to evaluate eLearning initiatives, to disseminate good practices and innovations in eLearning, and to conduct research into educational technologies.
The EPSU is a relatively small unit consisting of 4 dedicated staff: the Director, two instructional designers and a multimedia programmer. The rationale for establishing a small unit was that the eLearning Strategy calls for Faculties to appoint local eLearning Officers to support teachers with their eLearning requirements. The role of the EPSU is to liaise with the eLearning Officers in order to understand Faculty requirements and to provide additional dedicated support where required.

There are ten Faculties at the University of Hong Kong. Nine of the ten Faculties complied with the requirement to appoint an eLearning Officer. However, eight of the Faculties appointed individuals with a technical background. That is, the appointed eLearning Officers did not have a background in teaching and learning theory. This meant that the eLearning Officers were not instructional designers with the requisite knowledge to advise Faculties on how to make pedagogically principled use of technologies in teaching and learning. The exception was the Faculty of Education where the eLearning Officer was a relatively senior individual who taught two Masters Courses on the use of ICT in education.

It was the author's responsibility to develop an eLearning Certificate Course to teach the eLearning Officers the necessary practical and theoretical skills to support their Faculties with their eLearning requirements. The author developed the course during January and February 2012 and the course was offered over 12 weeks starting March 2012. eLearning Officers from nine of the ten Faculties 
enrolled. One Faculty sent two eLearning Officers. A colleague from the Centre for the Enhancement of Teaching and Learning also enrolled giving a total of eleven enrolments.

\section{Certificate Course Design}

The author was very aware that the majority of participants had no background in teaching and learning and that their focus was likely to be technical since the participants were computer officers / technical support within their respective Faculties. For this reason the course was developed in terms of a social constructivist pedagogical philosophy [1]. The constructivist element was given in the notion that the course needed to bring about a change in the participants' perspectives. The social element was given in an emphasis on the value of informing and being informed by the perspectives of all course participants.

The pedagogical approach was to present a different eLearning topic each week with content being delivered in 2 hour face to face sessions and through the Learning Management System Moodle. The topics were as follows: (1) Orientation and Introduction to eLearning (2) Learning and Learning Domains (3) Technologies in Teaching (4) The Role of the Teacher in eLearning (5) Assessment in eLearning (6) Quality in eLearning (7) Instructional Design Theory and Practice (8) Emerging Technologies and Cutting Edge eLearning (9) Connectivism (10) Being an Instructional Designer.

Participants were asked to view the content prior to coming to the two hour face-to-face session. The author delivered a brief presentation during each faceface-session with the presentation being followed by facilitated discussion on the topic for the week. After the face-to-face session participants were required to complete a key reading and to participate in a discussion forum activity. Each forum drew on the required reading and asked the participants questions about the topic for the week. The questions were deliberately crafted to enable participants to discuss and reflect upon eLearning as a way to enhance teaching and learning through making pedagogically principled use of technologies.

For example, the aim of the first week was to orient participants to the concept of eLearning and to encourage them to think about using technologies to enhance and enrich teaching and learning. Students were required to answer the following questions: (1) What experience do you have with the use of technologies in teaching and learning? (2) How does your experience fit with the model that this week's reading suggests for making purposeful use of technologies in teaching and learning? (3) What recommendations would you make to someone who asked you how to make purposeful use of technologies in teaching?

Whilst each topic engaged students with important eLearning principles and practices, the author was also concerned with scaffolding students to an in-depth understanding of what the course concepts would mean in their practice as eLearning Officers. To put this differently, the course needed to move students beyond acquiring information to a point where the students' conception of the use of technologies in teaching changed [2]. The change would be represented in terms of participants coming to understand that making purposeful use of technologies requires putting teaching first and seeing technologies as enablers of good practice.

The strategy for bring the students to this point of understanding was to have them in engage a collaborative and reflective wiki exercise. After discussion with the eLearning Officers a joint decision was made that the aim of the wiki exer- 
cise would be to reflect collaboratively on how the eLearning Certificate Course might help them to meet the challenges and realize the possibilities of eLearning within their Faculties. This aim was chosen because completing the wiki exercise would - in principle - require the participants to draw on the topics from all ten weeks of the course. The perceived success of this strategy - along with the perceived success of the course as a whole will be discussed in the next section of the paper.

\section{Certificate Course Analysis}

The Certificate Course was delivered over a ten week period starting 21st May. One participant withdrew in the first week citing the reason that the course focused on teaching / learning theory and was not therefore relevant for their Faculty role. Whilst only one student withdrew the majority of the remaining students also expressed the view that the course was not relevant to them. The reason for this was that they conceived of their role as purely technical. The author - also course facilitator - managed this issue by encouraging discussion about instructional design and through encouraging participants to think about the role of technologies in enhancing teaching and learning. The author also explained to the participants that one of the aims of the course was in fact to bring them to see that their role was one of being an instructional designer.

Evidence for the success of the course - with success initially being defined in terms of engagement - comes from the discussion forum postings. The author posted three discussion forum questions each week and participants were required to post at least once in response to the questions. Therefore, each participant had to post a minimum of ten times $(10 \times 1)$ during the course. Ethics approval was not sought for researching this course and so the author cannot present data on discussion forum postings. However, it will suffice to say that students engaged in posting at a level significantly in excess of course requirements. The view rate for postings is equally interesting. Again, actual data cannot be reported but the view rate was extremely high for all participants.

Looking at views and posts per se obviously only tells one activity levels within the course. There is no necessary correlation between activity levels and the quality or depth of engagement. For example, a student might post a substantial number of one sentence postings that display no understanding of the course material. This paper is not going to include an analysis of the discussion forum postings. However, in summary the quality of the postings was mixed as between participants and across the different forums. That said, all students produced quality postings and the posting rate understandably waned in the latter weeks of the course.

As previously stated participants struggled at the beginning of the course to see the relevance of the course to their roles within the Faculties. It was therefore very pleasing to see what happened in the wiki activity. Students had to work collaboratively to evidence an understanding of how the course related to their own work. One student produced a concept map showing the relationship between all the different course topics along with the relationship between the course topics and the role of eLearning Officers in the Faculties. This concept map provided the foundation for developing wiki pages that discussed challenges and opportunities in supporting Faculty with their eLearning needs.

The Certificate Course was evaluated using The University of Hong Kong's standard evaluation questionnaire. The 
questionnaire contains 10 items and students respond in terms of 5 point Likert scale ranging from "strongly agree" to "strongly disagree". There were nine $(\mathrm{N}=9)$ students at the end of the course and eight $(n=8)$ students completed the questionnaire. Again, in the absence of research ethics the evaluation data cannot be presented. However, the evaluations evidenced that the course had been very successful.

\section{Certificate Course Reflection}

If the course is judged in terms of student activity, depth of engagement and the end of course evaluations then the course can be said to have been successful. However, upon reflection the issue of the participants' expectations could have been more adequately addressed through making use of a theory of reflective learning for transformational change. The primary teaching challenge on this course was to have students question their assumptions so that they would become open to seeing themselves as potential instructional designers. Although the course was successful, the learning design might well have been more efficacious had it been explicitly premised on a theory of transformational learning.

Mezirow's work in this area suggests itself as potentially useful. According to Mezirow "Meaning perspectives refer to the structure of assumptions within which new experience is assimilated and transformed by one's past experience during the process of interpretation" [3]. The learning design might have surfaced students meaning perspectives through reflection "understood as an assessment of how or why we have perceived, thought, felt or acted" [4]. Appropriate reflective moments could have been achieved through a learning design that incorporated some key interaction types that would have cause participants to reflect and to achieve resolution as a result of their reflections.

This design approach also suggests an interesting research agenda. As previously stated professional learning is about developing the knowledge, skills and personal attributes to carry out one's professional duties. When professional learning fundamentally challenges a person's sense of who they are then one aim of the professional learning has to be to facilitate a change in self-understanding. Suitable pre and post course questionnaires would be able to elicit information that would indicate whether perspective change had occurred.

\section{Conclusions}

The operational reality with respect to eLearning at HKU in early 2012 meant that the Certificate Course had to be developed at speed. The course itself was solid in terms of design, development and delivery. However, now having the time to critically reflect on the course, the learning design might be altered to specifically address the issue of transforming participants to become instructional designers. The course will likely be offered again and the learning design suggested in this paper will be implemented.

\section{References}

[1] Jonassen, D. H. (1991). Objectivism Versus Constructivism: Do We Need A New Philosophical Paradigm? Educational Technology Research and Development, 39(3), 5-14.

[2] Grabinger, R. S., \& Dunlap, J. S. (1995). Rich Environments for Active Learning: A Definition. Association for Learning Technology Journal, 3(2), 5-34.

[3] Mezirow, J. (1990). How Critical Reflection Triggers Transformative Learning. Fostering Critical Reflec- 
tion in Adulthood: A Guide to Trans-

formative and Emancipatory Learn-

ing. San Francisco, CA.: Jossy-Bass

Publishers.

[3] Mezirow, J. (1990). How Critical Reflection Triggers Transformative Learning. Fostering Critical Reflection in Adulthood: A Guide to Transformative and Emancipatory Learning. San Francisco, CA.: Jossy-Bass Publishers. 